\author{
Mirosław Antonowicz \\ Kozminski University \\ e-mail: maaw@kozminski.edu.pl \\ Sebastian Jarzębowski \\ Kozminski University \\ e-mail: sjarzebowski@kozminski.edu.pl
}

\title{
THE PHYSICAL INTERNET AND DIGITAL SUPPLY CHAINS - SELECTED ISSUES
}

\begin{abstract}
Background: The physical Internet is a global system of closely related logistics network, based on efficiency and reliability is the use of linked interoperable logistical assets interoperable based on unified protocols collaboration, standard transport unit modular and intelligent interfaces. Today's supply chains are long and complex. This is connected with the fundamental problems that the physical Internet can reduce or eliminate. In terms of transport, which is still the way, untapped potential and transport space and inefficiencies in processes.
\end{abstract}

Methods: The research included within the paper is based on the results of the query sources, literature and case studies of companies developing and using digital technologies.

Results: Regardless of supply chains in the B2C relationships in recent years has undergone a real revolution driven by technological innovations. As is evident for example the report prepared by the Advisory company Deloitte in cooperation with the Association of MHI, the digital revolution also affects supply chains in manufacturing industry and B2B relationships. The greatest influence on changes to trends related to robotics and automation, data analytics, and Internet of things (IoT). Confirmation of the above trends we find in the report the company PwC. Thanks to the construction of the foundations of digital capture, analyze, integrate, use and interpret high-quality data in real time. These data are fueling process automation, predictive analytics, artificial intelligence and robotics, or technology that soon will take over to supply chain management. Within the paper the objectives and pillars of the physical Internet as well as strategic challenges and barriers have been identified. The state of the art of rail 
transport in Poland and Europe was highlighted, possible variants and solutions with regard to physical Internet have been discussed.

Keywords: The physical Internet, Digitization, Digital supply chain

\section{INTRODUCTION}

Information technology is penetrating every aspect of today's businesses; without a sound IT infrastructure companies cannot keep up with competitor firms who effectively use IT. Successful companies have already recognized this trend and have started to adapt - both to continually stay ahead of their competitors and to exploit the potential of digitalization to increase profit.

The environment, transport and logistics are relevant topics, within which the idea of the physical Internet and digitization of supply chains should be point of research. Goods flow processes in time and space (transport and logistics), their efficiency and reliability, affect the efficiency of business processes and determine the ability to timely, appropriate to meet the needs of individual clients and institutional players [Antonowicz \& Jarzębowski 2018].

The physical Internet is a global system of closely related logistics network, based on efficiency and reliability is the use of linked interoperable logistical assets interoperable based on unified protocols collaboration, standard transport unit modular and intelligent interfaces [Bellot \& Meller 2014]. The search for potential improvement of efficiency quickened with the realization that not only individual enterprises compete against each other but also entire supply chains [Christopher 1992]. Today's supply chains are long and complex. This is connected with the fundamental problems that the physical Internet can reduce or eliminate. From another point of view, to sustain long-term growth and profitability in a competitive environment, economic entities must continuously improve their efficiency [Sudit 1995]. In terms of transport, which is still the way, untapped potential and transport space and inefficiencies in processes.

Regardless of supply chains in the $\mathrm{B} 2 \mathrm{C}$ relationships in recent years has undergone a real revolution driven by technological innovations. As is evident for example the report [MHI 2017] prepared by the Advisory company Deloitte in cooperation with the Association of MHI, the digital revolution also affects supply chains in manufacturing industry and B2B relationships. The greatest influence on changes to trends related to robotics and automation,

Antonowicz M., Jarzębowski S., The Physical Internet and Digital Supply Chains - Selected Issues [in:] Adamczak M. et al., Digitalization of Supply Chains, Spatium, Radom 2019, p. 24-38. https://doi.org/10.17270/B.M.978-83-66017-86-3.3 
data analytics, and Internet of things (IoT). Confirmation of the above trends we find in the report the company PwC [PwC 2019]. Thanks to the construction of the foundations of digital capture, analyze, integrate, use and interpret high-quality data in real time. These data are fueling process automation, predictive analytics, artificial intelligence and robotics, or technology that soon will take over to supply chain management. Within the paper the objectives and pillars of the physical Internet as well as strategic challenges and barriers have been identified. The state of the art of rail transport in Poland and Europe was highlighted, possible variants and solutions with regard to physical Internet have been discussed.

\section{RESEARCH METCHODS}

One of the key drivers of this research is to deliver information and knowledge, essentially through two complementary approaches. Those are the systematization of information and data analyse on case studies of companies developing and using digital technologies.

These were identified through an extensive mapping on the basis of harmonized methodology and metrics on what qualifies something as a suitable case study in terms of results, as well as its replicability potential. Experiences that can be qualified as sustainable ware taken in to the consideration. The systematic literature review and work on case studies allowed to identify key issues (strategic challenges) around physical internet and digital technologies

\section{POLAND ON THE WORLD TRANSPORT MAP}

Poland lies at the crossroads of transit routes from east to west and from south to north. Its geographical location in the centre of Europe and its friendly, lowland terrain and temperate climate mean that many transit routes of great intra- and intercontinental importance pass through it [Jarzębowski \& Bezat-Jarzębowska 2013].

Four Pan-European Transport Corridors (TINA) numbered I, II, III and VI run through Poland, as well as key EU freight corridors (Figure 1), Baltic Sea - Adriatic Sea (RFC 5) and North Sea - Baltic Sea (RFC 8) within the meaning of the Regulation of the European Parliament and of the Council 13/2010 on the European rail network for competitive freight and freight corridors within the TEN-T core network [Regulation ...2010]. 


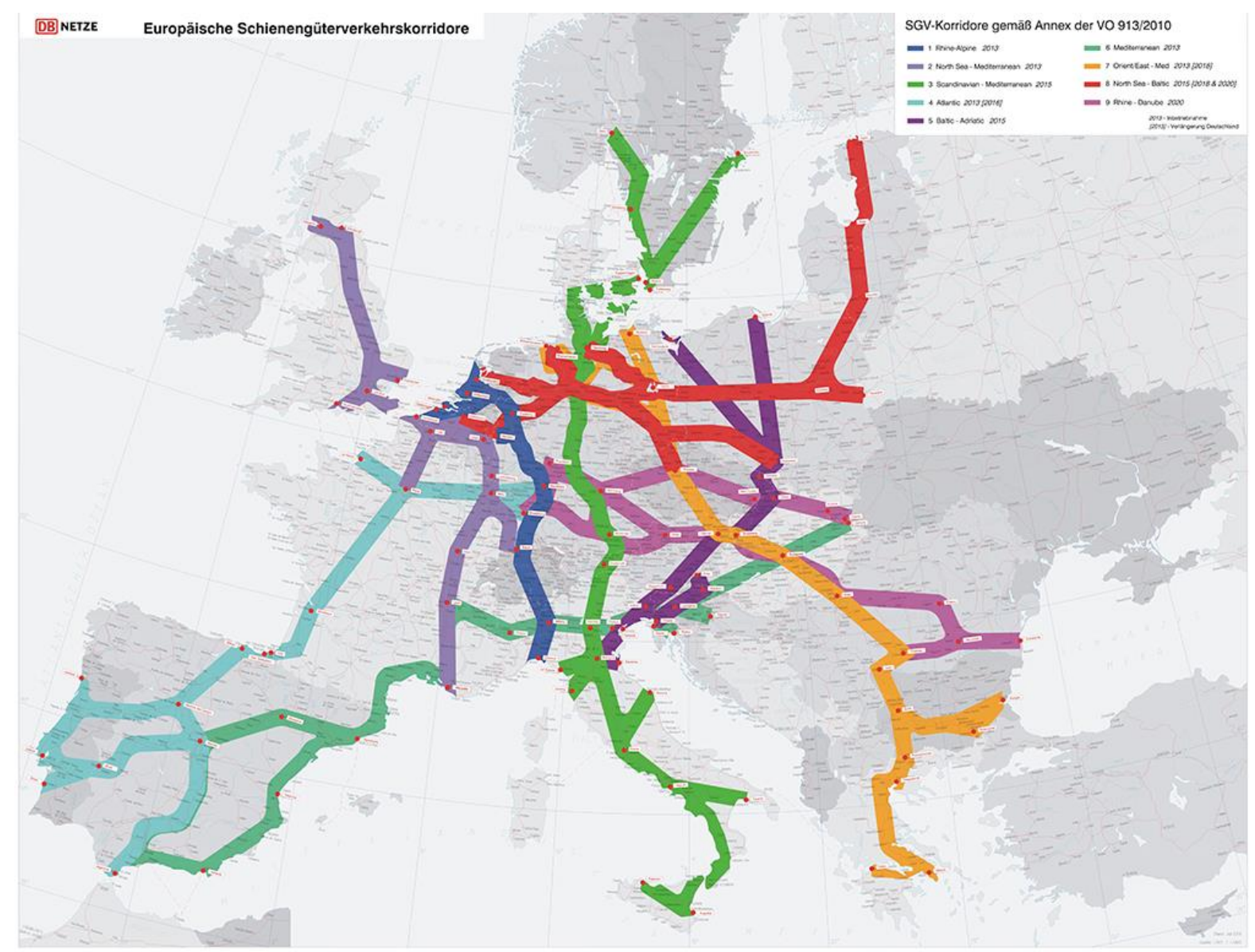

Fig. 1: Main freight corridors through Europe.

Source: [Three EU Rail Freight Corridors launched, 2015].

The RFC 8 corridor, which is a natural extension of the New Silk Road rail route within the territory of the European Union, is of particular importance for trade between China and the European Union. China remains a world leader in foreign trade, both in terms of exports and imports [WTO, 2018], Among the EU's trading partners, China was the largest partner for EU imports of goods, and the second largest partner for EU exports of goods in 2017, while the European Union remains the main trading partner of the China, accounting for $20 \%$ of its international economic exchange [Eurostat, 2018].

Given the particular importance of the Polish infrastructure for rail freight between China and the EU, the Polish authorities, with the support of the EU, carried out extensive measures to modernize the existing linear and nodal infrastructure between 2007 and 2015.

Antonowicz M., Jarzębowski S., The Physical Internet and Digital Supply Chains - Selected Issues [in:] Adamczak M. et al., Digitalization of Supply Chains, Spatium, Radom 2019, p. 24-38. https://doi.org/10.17270/B.M.978-83-66017-86-3.3 
The financing of investment projects approved in the "Strategy for Responsible Development" is to be provided primarily by the EU budget from the Operational Programme Infrastructure and Environment in the amount of EUR 12.172 billion dedicated to the modernization of, among others, railway lines. Between 2007 and 2015, the quality of rail transport infrastructure in Poland increased substantially. The proportion of lines in good technical condition rose from $25 \%$ to $55 \%$, while the share of lines in an unsatisfactory technical condition fell from $28 \%$ to $16 \%$. The large-scale of modernisation and revitalisation projects, implemented with support from EU funds, have increased the attractiveness of rail in Poland [Bień \& Wójcik-Mazur 2014].

Poland has not only established better transport connections with neighbouring countries of the European Union, but has also prepared a plan of coordinated actions in form of National Railway Programme until 2023 (NRP), which was adopted via a resolution of the Council of Ministers from September 15, 2015 (updated in November 2016) to become a gateway to the European Union.

PKP S.A. conducts works aimed at developing its real estate for the development of railway nodal infrastructure facilities, including logistics centres and transshipment terminals. The company has selected a portfolio of properties all over Poland, which may be used for the development of logistics infrastructure, and in the near future it plans to develop these areas. This action is also part of the initiative to create in Poland a logistics platform serving the markets of Central and Eastern Europe, which would be able to handle the increasing flows of cargo transported (not only by rail) between China and Europe.

The Central Transport Port (CTP) is the concept of a high-capacity logistics centre with good road and rail access. A natural advantage of CTP, apart from its central location in Poland and good access to motorways, would be the possibility of combining on the first and last miles of cargo transported by different modes of transport between distant locations, taking into account the main transport corridors. In addition, PKP Group companies have taken a number of initiatives aimed at removing transport barriers, which have been highlighted by the Chinese side.

In order to eliminate the risk of lack of container transport platforms, PKP CARGO announced on 4 September 2018 a tender for the purchase of 936 intermodal platforms; at the 
end of the year the company also received EU funding for the purchase of another 220 container transport platforms dedicated to international transport. In total, in the years 2018-2023, PKP CARGO S.A. planned to purchase over 1000 wagons-platforms, which will improve the transport process and ensure greater reliability of operation.

PKP CARGO has also taken important measures in terms of insufficient productivity of information exchange. Mechanisms are being developed for providing information on wagons and containers on trains travelling from China to Europe before their physical arrival at the border crossing points, as well as railway and customs documentation necessary to cross the external customs border of the European Union. This optimizes the use of resources and speeds up rail and customs formalities, which has a significant impact on the total time it takes for containers to be transported by rail from China to EU countries. Currently, efforts are being made to obtain the necessary data after the transshipment of trains at border crossings in China $(1435 \mathrm{~mm}) / 1520 \mathrm{~mm}$ railways (Kazakhstan, Mongolia, Russia), which would give at least a few days of reserve to prepare for the acceptance of the train to the network in Poland, customs and border clearance of shipments, transshipment of containers, and the formation of trains for their final transport to terminals of destination on the European rail network.

A system for the mutual exchange of information between railways on container streams to be carried and in the event of unexpected obstacles to transport has also been developed, thus largely preventing congestion at $1520 \mathrm{~mm}$ and $1435 \mathrm{~mm}$ border junctions as well as at border and destination transshipment terminals.

Moreover, in order to shorten customs procedures at the Polish-Belarusian border, which is the last of the operational barriers to the development of NSR transport indicated by Sinotras (Song, 2016), at the Terespol-Brest crossing point, a pilot TORY-24 programme was introduced by the Ministry of Finance. Its aim is to streamline the processes of handling foreign trade in rail traffic carried out by services, inspectorates, carriers and other institutions operating in Małaszewicze. This tool enables all participants in the freight traffic management process to participate in the exchange of information. The duration of custom clearance of goods imported from third countries carried out by the services and inspections should not exceed 24 hours from the time when the goods are placed under control to the competent authorities.

Antonowicz M., Jarzębowski S., The Physical Internet and Digital Supply Chains - Selected Issues [in:] Adamczak M. et al., Digitalization of Supply Chains, Spatium, Radom 2019, p. 24-38. https://doi.org/10.17270/B.M.978-83-66017-86-3.3 
The implementation of the traffic management and control coordination mechanism (TORY-24, English: TRACKS-24) makes it possible to improve the handling of trade in goods through:

- Faster electronic exchange of information,

- Availability of information for users operating in different locations,

- Coordinating the place and time of the inspection of goods,

- Possibility of monitoring the process of handling the trade of goods.

The carrier/forwarder/customs agency/postal operator is given the opportunity to participate directly in the freight handling process from the moment of entry of the train, submission of the request for an inspection to the relevant service/inspectorate, transmission or acquisition of information on the time and place of inspection and its results. The services will receive advance information (advice) about the intention to submit an application for control by the dispatcher of the goods, which allows for effective work planning and enables the exchange of additional information between users at each stage of the control process.

Companies from the PKP Group work on the development of technologies and innovative solutions to support intermodal transport. One of the possible actions to improve the movement of loads across the Polish eastern border is also the implementation on a wider scale of a system for automatic gauge changing (the most promising seems to be the second generation of the SUW-2000 system), which would allow reloading-free movement of railway consignments through the $1435 \mathrm{~mm}$ and $1520 \mathrm{~mm}$ gauge intersections. However, it would take several years from verification of a greater long-term interest in using such a solution to its possible commercial implementation to refine the configuration of the implemented variant of the system and then test it and start serial production of variable-track axle sets to be used in freight wagons and to construct track gauge setting points at the interface between tracks of different gauges, through which it will be possible to change the track width automatically without unloading or changing wagons or their bogies.

Antonowicz M., Jarzębowski S., The Physical Internet and Digital Supply Chains - Selected Issues [in:] Adamczak M. et al., Digitalization of Supply Chains, Spatium, Radom 2019, p. 24-38. https://doi.org/10.17270/B.M.978-83-66017-86-3.3 
Table 1. Variants of cargo movement at the contact point of different track widths

\begin{tabular}{|c|c|c|c|c|c|c|}
\hline \multirow{2}{*}{ Variant } & \multirow{2}{*}{ Name } & \multirow{2}{*}{$\begin{array}{l}\text { Method of } \\
\text { operation }\end{array}$} & \multirow{2}{*}{$\begin{array}{l}\text { Operating } \\
\text { time (min.) }\end{array}$} & \multicolumn{2}{|c|}{ Calculation performance } & \multirow{2}{*}{ Versatility } \\
\hline & & & & weight/hour & tonnes/hour & \\
\hline I & $\begin{array}{l}\text { Cistern-cistern } \\
\text { pumping }\end{array}$ & Overflow station & 40 & 1,5 & 90 & $\begin{array}{l}\text { Required } \\
\text { technological stock } \\
\text { of wagons }\end{array}$ \\
\hline II & $\begin{array}{l}\text { Transshipment of } \\
\text { cargo units }\end{array}$ & Transshipment berth & 6 & 10 & 215 & Full \\
\hline III & $\begin{array}{l}\text { Replacement of } \\
\text { trolleys with body lift }\end{array}$ & Resetting station & 20 & 3 & 180 & $\begin{array}{l}\text { Required } \\
\text { technological stock } \\
\text { of trolleys }\end{array}$ \\
\hline IV & $\begin{array}{l}\text { Automatic Gauge } \\
\text { Changing Systems }\end{array}$ & $\begin{array}{l}\text { Continuous, with the } \\
\text { use of a resetting } \\
\text { station }\end{array}$ & 0,5 & 120 & 7200 & $\begin{array}{l}\text { Carriage in single } \\
\text { wagons, in groups } \\
\text { or full-train }\end{array}$ \\
\hline
\end{tabular}

Source: own elaboration.

The application of the mechanism would allow for a significant acceleration of transport across Poland's eastern border and would also increase the reloading capacity of the largest transshipment terminals located at the junction of railway lines with different rail gauge.

\section{STRATEGIC CHALLENGE FOR RAIL TRANSPORT IN THE AREA OF LOGISTICS $^{1}$}

A combination of a strategic concept and the technology of its implementation, which is a value chain that allows for the effective exploitation and renewal of resources and skills [Obłój 2002]. For the transport and logistics in the field of rail services in order to improve the effectiveness and efficiency of transport processes, consider the idea of physical Internet. Goods flow processes in time and space (transport and logistics), their efficiency and reliability affects

\footnotetext{
${ }^{1}$ Uses elements of: STRATEGY OF PKP S.A. AS AN INSTRUMENT OF POLISH RAILWAY TRANSPORT DEVELOPMENT
}

Antonowicz M., Jarzębowski S., The Physical Internet and Digital Supply Chains - Selected Issues [in:] Adamczak M. et al., Digitalization of Supply Chains, Spatium, Radom 2019, p. 24-38. https://doi.org/10.17270/B.M.978-83-66017-86-3.3 
the efficiency of business processes and determines the ability to timely and appropriately meet the needs of individual and institutional clients using those services via railway transport.

The physical Internet is a global system of closely related logistic networks, based on efficiency and reliability. It is based on the use of linked interoperable logistical assets which use an unified collaboration protocols, intelligent interfaces and standardized modular transport unit [Bellot \& Meller 2014].

Modern transport chains are long and complex e.g. rail transport chains of the New Silk Road. Some of the fundamental problems that the idea of the physical Internet can reduce or eliminate are unused space, transport inefficiencies in processes as a result of the lack of integration of systems and the lack of intelligent interfaces [Antonowicz 2018].

The idea and the basic objectives of the physical Internet shows the Fig. 2.

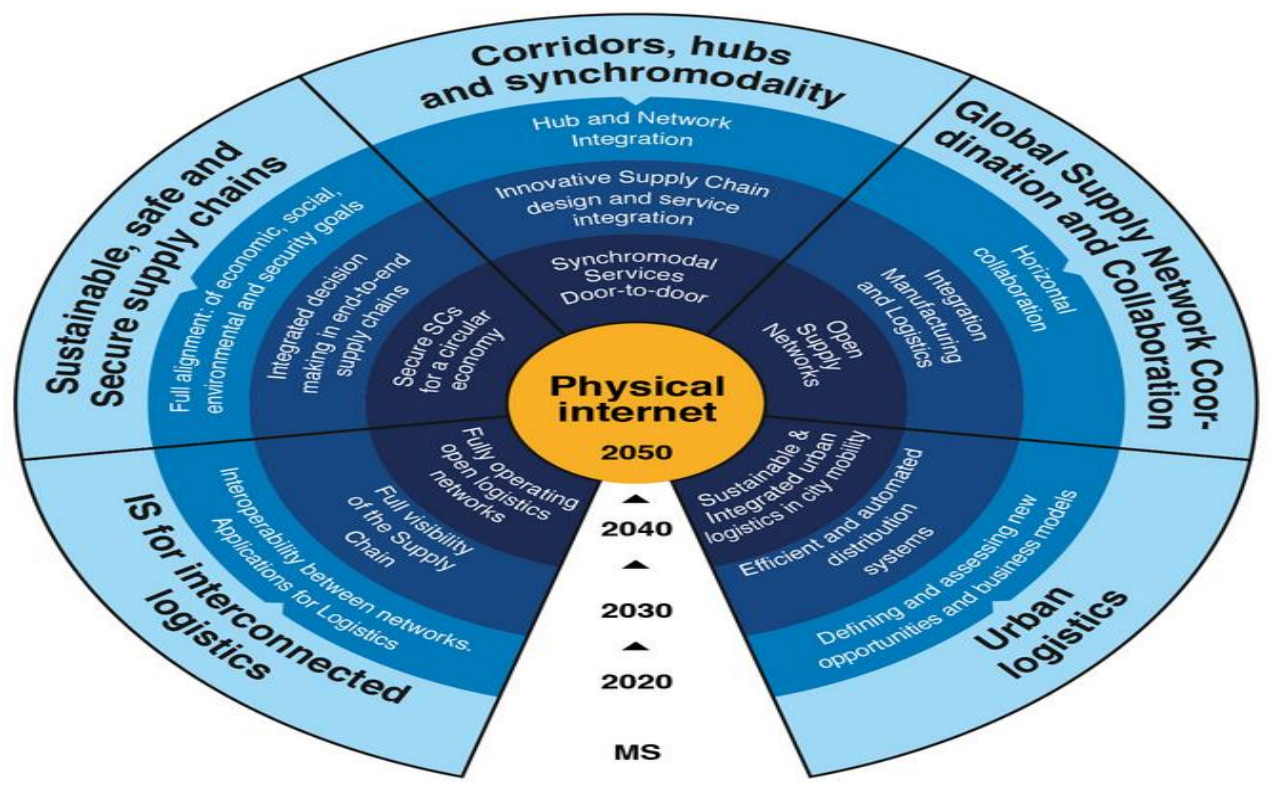

Fig. 2. Idea and basic objectives of the physical Internet.

Source: [Alice 2014].

The basic objectives are:

- More than twofold increase in the efficiency of logistics (taking into account the benefits of the redirection of already sent shipments),

Antonowicz M., Jarzębowski S., The Physical Internet and Digital Supply Chains - Selected Issues [in:] Adamczak M. et al., Digitalization of Supply Chains, Spatium, Radom 2019, p. 24-38. https://doi.org/10.17270/B.M.978-83-66017-86-3.3 
- Improvement of the reliability of the flow of goods achieved through fast, automated supply chains based on complex information about the difficulties and dangers,

- Better use of human resources, hardware and infrastructure,

- Significant reduction of greenhouse gas emission in land transport,

- Increase in innovative logistics solutions.

As it appears from conducted in the U.S. research, physical Internet proposes a system in which the global logistics supply chains are connected by an open intermodal system (pie, railway, shipping-barges and ships) that uses standard, modular, reusable containers, identification and coordination of routes in real time by shared logistics centres. Producers, shipments senders, transport operators operate independently, using shared logistic networks, which increase the load of vehicles, wagons, boats, and reduce empty mileage of vehicles [Antonowicz et al. 2018]. Pillars of physical Internet are shown in the Fig. 3.

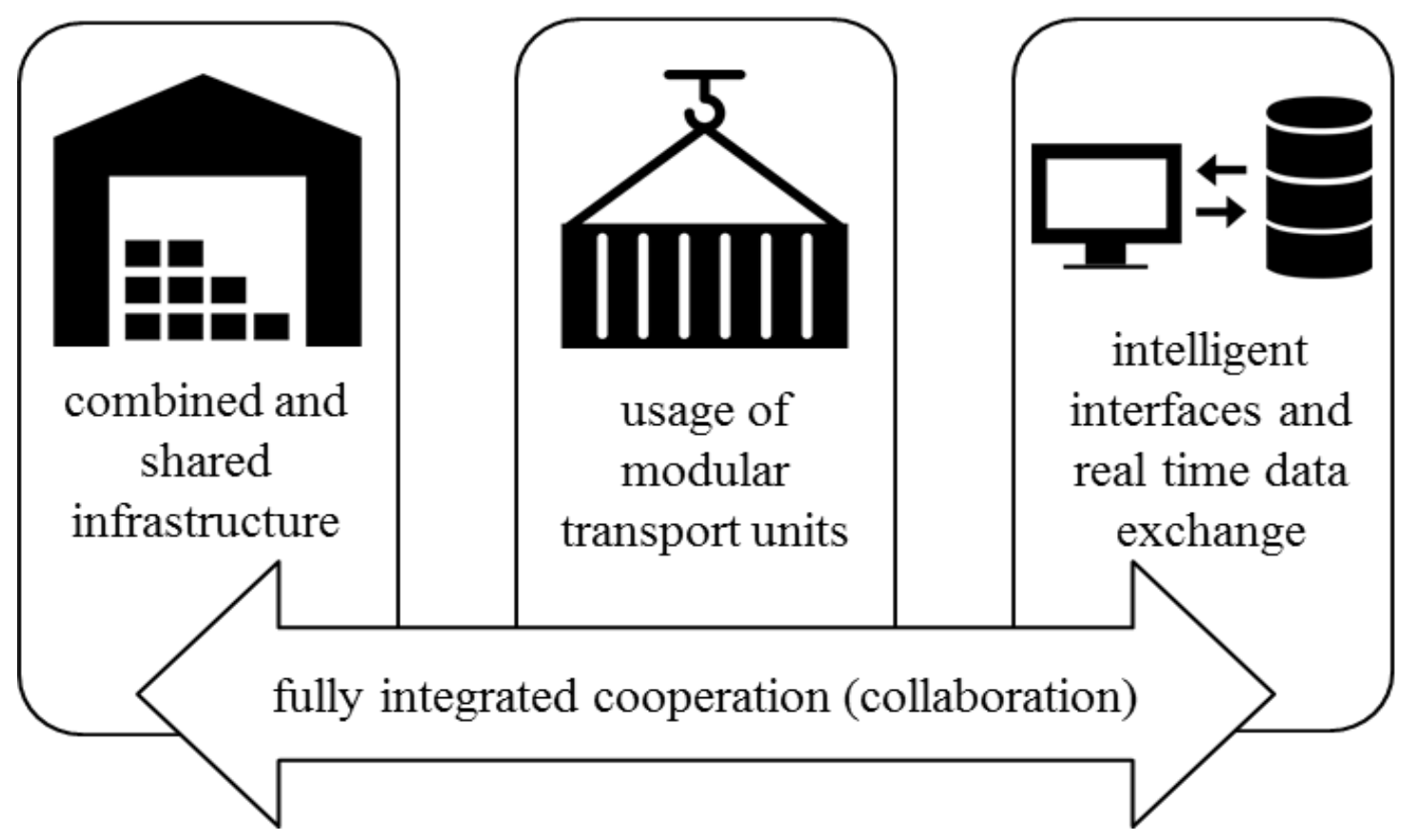

Fig. 3. The pillars of the physical Internet.

Source: own elaboration based on: [Zdziarska \& Hachuła 2015].

Antonowicz M., Jarzębowski S., The Physical Internet and Digital Supply Chains - Selected Issues [in:] Adamczak M. et al., Digitalization of Supply Chains, Spatium, Radom 2019, p. 24-38. https://doi.org/10.17270/B.M.978-83-66017-86-3.3 
Therefore, the aim of most of the logistics activities in PKP Group are potential sources of benefits of constructing of a global logistics system based on the concept of the physical Internet:

- A significant increase of intermodal transport magnitude obtained by standardization and usage of modular transport units (intermodal is the most perspective segment of rail services)

- Generating a huge pool of orders for railway transport as a result of suggesting shipments senders to plan the decision process via a computer system that takes into account a variety of multimodal options.

For the achievement of these benefits first and last mile rail road freight terminals, managed under the idea of the physical Internet, should have adjacent warehouses and grading plant and increased length of the railway loading track which would enhance capabilities to simultaneously manage and handle the transhipment point of many trucks.

Sample layout of the Terminal for intermodal rail transport-road shows the Fig. 4.

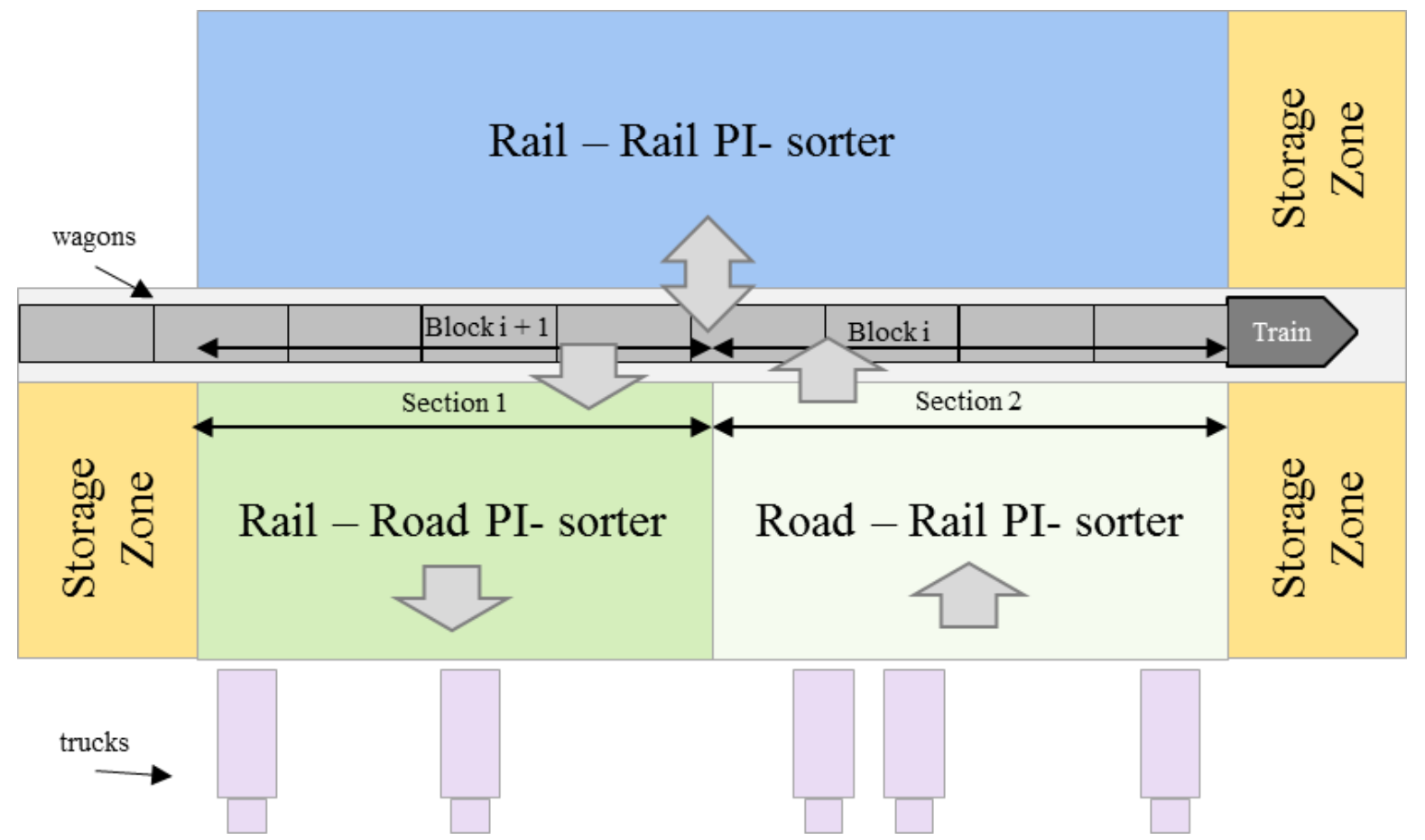

Fig. 4. Example of the layout of the Terminal in the concept of the physical Internet.

Source: own elaboration based on: [Antonowicz \& Zaremba 2019] .

Antonowicz M., Jarzębowski S., The Physical Internet and Digital Supply Chains - Selected Issues [in:] Adamczak M. et al., Digitalization of Supply Chains, Spatium, Radom 2019, p. 24-38. https://doi.org/10.17270/B.M.978-83-66017-86-3.3 
The implementation of this idea is conditioned on improvement of clarity of collaboration rules with various stakeholders in order to acquire goods for common supply chains, integration and implementation of investment processes and business, competence development and deployment the latest solutions and techniques to optimize logistics processes, promotion of multi-modal services and the organic forms of transport.

\section{THE ROLE OF THE CONCEPT OF THE PHYSICAL INTERNET TRANSPORT}

When considering the following options on the assumption that:

- new variant of zero indicates no grouping of cargo transport,

- option 1 means car transport aggregate loads,

- option 2 assumes the grouping of loads with optional use of railways,

- option 3 contains a grouping of loads with optional use of railways and cross-docking.

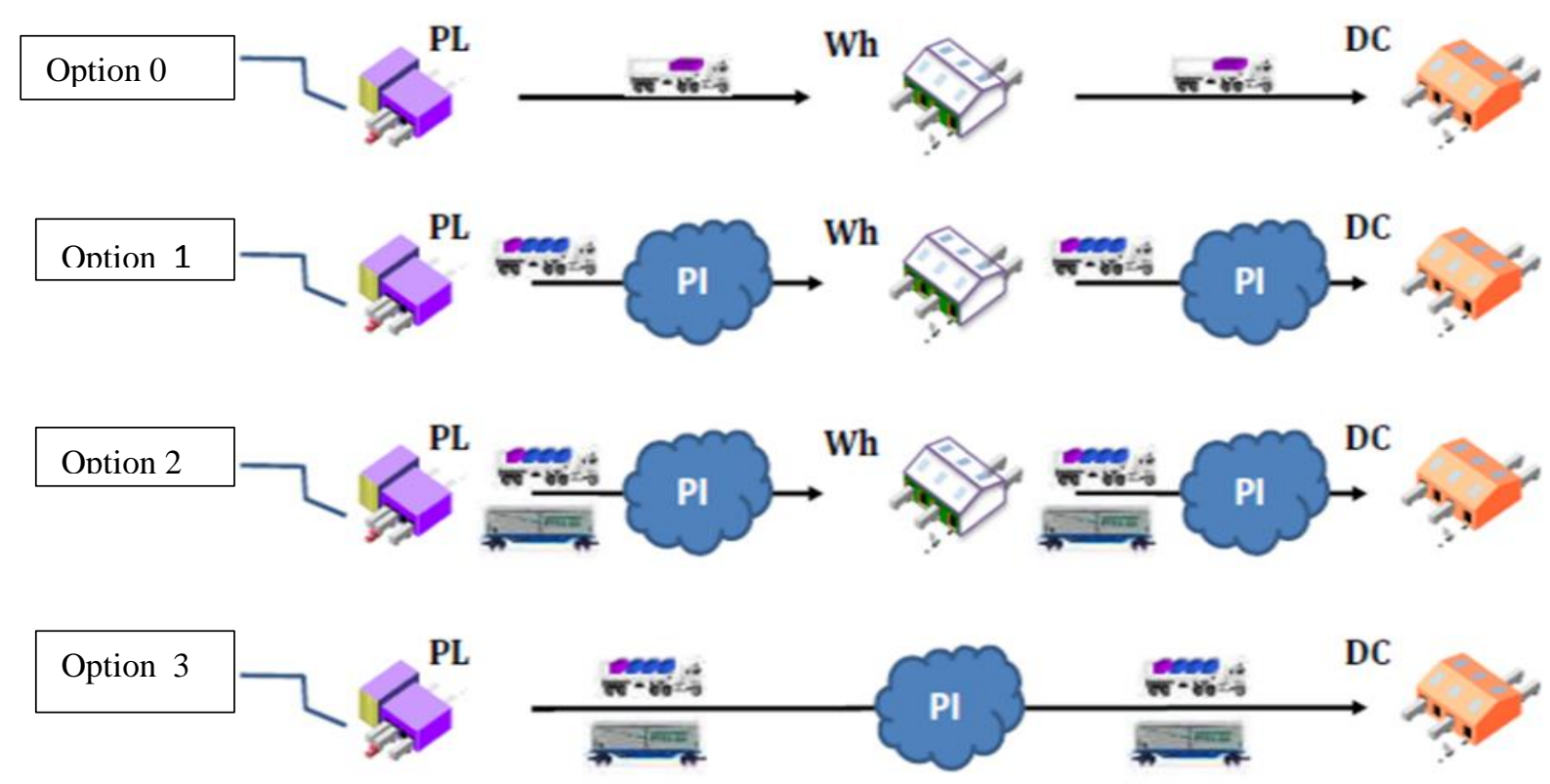

Fig. 5. The potential cost and environmental history of the concept of the physical Internet connection associated with the Assembly of consignments and choice of modes of transport.

Source: own elaboration based on: [Antonowicz \& Zaremba 2019].

Cost and environmental potential of the concept of the physical Internet connection associated with the merger of consignments from different senders on the routes of carriage is significant (see Fig. 5). By making a relative comparison of logistics costs arising on stage between

Antonowicz M., Jarzębowski S., The Physical Internet and Digital Supply Chains - Selected Issues [in:] Adamczak M. et al., Digitalization of Supply Chains, Spatium, Radom 2019, p. 24-38. https://doi.org/10.17270/B.M.978-83-66017-86-3.3 
production facility and distribution center retailer it is estimated that the consignments of enumerable shipment in modular units of transport solutions bimodal and cross- dockingu logistics costs from the production plants to the city center the distribution network can take to reduce by up to $32 \%$ and $\mathrm{CO} 2$ emissions reduced by $60 \%$. While the use of rail transport in the concept of the physical Internet reduces $\mathrm{CO} 2$ emissions by up to $80 \%$ compared to road transport by combined logistics on the basis of the physical Internet.

Given the above ramblings market challenges for the combined logistics based on the idea of the physical Internet are the following:

- price, delivery times and conditions acceptable for most target customers,

- transparent deals on full service packages from the original origin to destination target,

- instantly generate quotes for services using multiple means of transport (including multimodal) in response to a query,

- the ability to modify the customer routes or expected time of delivery or target destinations for all or a lot of loads already once shipments,

- the popularization of multi size modular packaging, that can be easily aggregated into larger standard transport units on the market.

This means that the development of the physical Internet connection will result in a fully integrated network that support movements of goods in the standard modular packaging.

\section{CONCLUSIONS}

As companies continue to grow and expand into new markets, the need for increased IT integration is a must. Enterprise technologies can be the backbone of an organization's global operation. In order to remain competitive, enterprises must continually develop and identify new solutions, implemented through constant investments and the introduction of new technologies. This underlines the ability to stimulate economic activity with the potential to create jobs for regions in need of economic development. One way is indeed to improve entrepreneurial competencies and skills through the innovative potential in IT architecture creation. The speed and scale at which business is conducted today requires intense coordination of business processes; enterprise technologies give companies the ability to operate at speed and scale demanded in today's business world. 
The aim of the paper is an indication of the ability to apply the idea of the physical Internet and an indication of the role of modern technology in the management of modern supply chain. The research included in the paper is based on the results of the query sources, literature and case studies of companies developing and using digital technologies. Within the paper the objectives and pillars of the physical Internet as well as strategic challenges and barriers have been identified. The state of the art of rail transport in Poland and Europe was highlighted, possible variants and solutions with regard to physical Internet have been discussed.

\section{REFERENCES}

Alice (2014): Alliance for Logistics Innovation through Collaboration in Europe, https://www.etp-logistics.eu

Antonowicz M. (2018): THE STRATEGIC DIMENSION OF LOGISTICS IN THE FOURTH RAILWAY PACKAGE, RESEARCH JOURNAL OF THE UNIVERSITY OF GDAŃSK, Vol. 78 (2018)

ANTONOWICZ M., JARZĘBOWSKI S. (2018): Innovative Models of Supply Chain

Management, Journal of Management and Business Administration. Central Europe, Vol. 26, No. 2/2018, p. 2-15

ANTONOWICZ M., JARZĘBOWSKI S., GONSIOR T. (2018): Internet rzeczy i jego wpływ na łańcuch dostaw, PRZEDSIĘBIORCZOŚĆ I ZARZĄDZANIE, 5 cz.I, s.295-310

Antonowicz M., Zaremba M. (2019): Collaboration of multimodal terminal operators based on Physical Internet idea - implementation challenges and expected advantages, International Scientific Conference Transport of then 21 st. Century, RYN 9-12 June 2019.

Bellot E., Meller R. (2014): Colloque de l'Ort21 Internet Physique, Observatoire Régional des Transports et de la Logistique de Lorraine

Bień E., Wójcik-Mazur A. (2014): The effective use of EU funds for environmental activities in the Operational Program Infrastructure and Environment (OP I\&E), Desalination and Water Treatment, 52:19-21, 3871-3878

Christopher, M. (1992). Logistics and Supply Chain Management - Strategies for Reducing Costs and Improving Services. London: Pitman Publishing.

Eurostat (2018): https://ec.europa.eu/eurostat

Antonowicz M., Jarzębowski S., The Physical Internet and Digital Supply Chains - Selected Issues [in:] Adamczak M. et al., Digitalization of Supply Chains, Spatium, Radom 2019, p. 24-38. https://doi.org/10.17270/B.M.978-83-66017-86-3.3 
JARZĘBOWSKI S., Bezat-Jarzębowska A. (2013): Central and Eastern Europe in: Global Supply Chains: Evaluating Regions on an EPIC Framework - Economy, Politics, Infrastructure, and Competence, Mandyam M. (Srini) Srinivasan, Theodore P. (Ted) Stank, Philippe-Pierre Dornier, Kenneth J. Petersen, MCGRAW HILL EDUCATION, s.315-350 MHI Annual Industry Report Next-Generation Supply Chains (2017): Digital, On-Demand and Always-On National Railway Programme until 2023 (NRP)

Obłój, K. (2002). Tworzywo skutecznych strategii. Warszawa: PWE

PKP (2019): Strategy of PKP S.A. as an instrument of Polish railway transport development

PwC (2019): Transport and Logistics Trendbook

Railway Gazette (2015): Three EU Rail Freight Corridors launched, Railway Gazette $12 / 11 / 2015$

Regulation of the European Parliament and of the Council 13/2010 on the European rail network for competitive freight and freight corridors within the TEN-T core network.

Sudit, E.F. (1995). Productivity management in industrial operations. European Journal of Operational Research, 85(3): 435-543

WTO (2018): https://www.wto.org/

Zdziarska M., Hachuła P., (2015): Physical Internet-future logistics, Institute of Logistics and Warehousing, Poznan. 